\title{
An ultra-high dose of electron radiation response of Germanium Flat Fiber and TLD-100
}

\author{
A. Alawiah ${ }^{\mathrm{a}, *, 1}$, Y.M. Amin ${ }^{\mathrm{a}}$, H.A. Abdul-Rashid ${ }^{\mathrm{b}}$, W.S. Wan Abdullah ${ }^{\mathrm{c}}$, M.J. Maah ${ }^{\mathrm{d}}$, \\ D.A. Bradley ${ }^{a, e}$ \\ ${ }^{a}$ Radiation Laboratory, Physics Department, Faculty of Science, University of Malaya, 50603 Kuala Lumpur, Malaysia \\ ${ }^{\mathrm{b}}$ Fiber Optics Research Center, Faculty of Engineering, Multimedia University, 63100 Cyberjaya, Selangor, Malaysia \\ ${ }^{\mathrm{c}}$ Nuclear Malaysia Agency, ALURTRON, 43000 Bangi, Selangor, Malaysia \\ ${ }^{d}$ Chemistry Department, Faculty of Science, University of Malaya, 50603 Kuala Lumpur, Malaysia \\ e Department of Physics, University of Surrey, Guildford, Surrey GU2 7XH, United Kingdom
}

\section{H I G H L I G H T S}

- The supralinearity of GFF and TLD-100 was highly dependent on the UHD.

- The maximum supralinearity $f(D)$ max of TLD-100, occurs around $10 \mathrm{kGy}$.

- TL kinetic model can be used to explain the glow peak behavior of doses $<f(D)$ max.

- The supralinearity response decreases for doses above the critical dose limit.

\section{A R T I C L E I N F O}

\section{Article history:}

Received 29 January 2016

Received in revised form

10 July 2016

Accepted 11 July 2016

Available online 13 July 2016

Keywords:

Critical dose limit

Ultra-high dose

TL kinetic model

Supralinearity

Glow curve

Glow peak

\begin{abstract}
A B S T R A C T
The thermoluminescence (TL) response of Germanium Flat Fiber (GFF) and TLD-100 irradiated with 2.5 MeV electrons for the doses up to $1 \mathrm{MGy}$ were studied and compared. The aim was to evaluate the TL supralinearity response at an ultra-high dose (UHD) range and to investigate the change in kinetic parameters of the glow peaks, as the doses increases up to $1 \mathrm{MGy}$. It is found that the critical dose limit (CDL) of GFF is 5 times higher as compared to TLD-100. CDL is determined by the dose at the maximum supralinearity, $f(D)_{\max }$. It is also found that annealing the TLD-100 and GFF with temperature more than $400^{\circ} \mathrm{C}$ is required to reset it back to its original condition, following radiation doses up to $1 \mathrm{MGy}$. It is also noticed the strange behavior of Peak 4 (TLD-100), which tends to be invisible at the lower dose $(<10 \mathrm{kGy}$ ) and starts to be appeared at the critical dose limit of $10 \mathrm{kGy}$. This result might be an important clue to understand the behavior of TLD-100 at extremely high dose range. For both samples, it is observed that the TL intensity is not saturated within the UHD range studied.
\end{abstract}

(c) 2016 Elsevier Ltd. All rights reserved.

\section{Introduction}

Thermoluminescence (TL) dosimetry at high dose radiation has attracted much attention as increasing needs in food safety, radiation protection on an extreme dose field and nuclear reactor dose monitoring. Therefore, it is crucial to reveal the performance of a dosimeter under circumstances of high dose deposition, and investigate the TL mechanisms, including the TL glow curve response and glow peak behavior, especially in the supralinearity dose response.

\footnotetext{
* Corresponding author.

E-mail address: alawiahofd@gmail.com (A. Alawiah).

${ }^{1}$ https://malaya.academia.edu/ALAWIAHARIFFIN.
}

There are some findings from the Institute of Nuclear Physics (IFJ), Poland related to MTS-N which is equivalent to TLD-100 (IJF); (1) The TL response of TLD-100 (IJF) following high doses of ${ }^{60} \mathrm{Co}$ gamma rays revealed a new peak at the temperature of $420{ }^{\circ} \mathrm{C}$ for doses exceed 700 kGy by Khoury et al. (2011); (2) Bilski et al. (2010) found that two glow peaks dominated at $5 \mathrm{kGy}$ with peak temperatures of $340{ }^{\circ} \mathrm{C}$ and $370{ }^{\circ} \mathrm{C}$ and saturated at $50 \mathrm{kGy}$; (3) A small peak was observed near $500{ }^{\circ} \mathrm{C}$ following irradiation of $20 \mathrm{kGy}$ reported by Obryk et al. (2010) using $24 \mathrm{GeV} / \mathrm{c}$ protons. On the other hand, Montaño-Garcia and Gamboa-deBuen (2006) investigated the response of TLD-100 (Bicron) to high doses of ${ }^{60} \mathrm{Co}$ gamma rays and observed a significant increase in TL intensity of the peaks 5 and 7 within the range of $2.5 \mathrm{kGy}$ to $7 \mathrm{kGy}$ and then TL decreases with further increases in dose. Glow curves were deconvoluted into single first-order peaks using GlowFit ${ }^{\mathbb{B}}$, a program developed by IFJ (Puchalska and Bilski, 2006). 
However, none of these works have adequately addressed the limitation of TL response at extremely high doses of electron radiation. Despite much excellent work on TL dosimetry such as dose linearity response and TL glow curve, scholars examining the TL behavior in the clinical dose range, have not yet fully explored the importance of supralinearity and critical dose limit, in an ultrahigh dose radiation field. Yet, without such an understanding, we are left with an inadequate analysis that creates the condition for misinterpretation of the TL glow curve and main dosimetric peak evaluation and improper of kinetic model implementation.

This study will remedy this gap in the literature by examining the TL supralinearity response and determine the critical dose limit of GFF and TLD-100, in order to reveal more connections between the supralinearity behavior and the kinetic parameters of the specific high dose radiation field. The aim of this paper is to evaluate the TL glow curve response by using WinREMS ${ }^{\circledR}$ software and determine its kinetic parameters by using WinGCF ${ }^{\text {if }}$ software deconvoluted glow peaks in the UHD region of interest.

\section{Experimental procedure}

The TLD-100 chips $(3.0 \mathrm{~mm} \times 3.0 \mathrm{~mm} \times 0.89 \mathrm{~mm})$ were obtained from the Harshaw-Bicron Company. The GFF samples used were fabricated with $6 \mathrm{wt} \%$ of Germanium dopant, by the Fiber Optic Research Center, Multimedia University, Malaysia. In this study, the samples were annealed using a Nabertherm Program Controlled S27 Furnace (Nabertherm ${ }^{\circ}$, Germany) at $400{ }^{\circ} \mathrm{C}$ for $1 \mathrm{~h}$. At the end of the heat treatments, the samples were quickly cooled in air to the room temperature (RT) by placing them on an aluminum block. The cooling rate is estimated at $16^{\circ} \mathrm{C}$ per minute.

The samples were irradiated with $2.5 \mathrm{MeV}$ electrons at doses ranging from $1 \mathrm{kGy}$ to $1 \mathrm{MGy}$ at RT (ALURTRON ${ }^{\mathrm{ki}}$, Nuclear Malaysia Agency, Bangi, Malaysia). The TL yield as a function of temperature, referred to as the TL glow curve, were obtained by WinREMS $^{\mathbb{B}}$, which is the operating system for the Harshaw ${ }^{\mathbb{B}}$ TLD reader, model 3500 (Thermo Fisher Scientific Inc, U.S.A). During readout the following parameters were used: preheat temperature of $60{ }^{\circ} \mathrm{C}$ for $5.0 \mathrm{~s}$; acquisition temperature of $400{ }^{\circ} \mathrm{C}$ for $116 \frac{2}{3} \mathrm{~s}$ and a linear heating rate of $3{ }^{\circ} \mathrm{C} \mathrm{s}^{-1}$. All readings were taken under $\mathrm{N}_{2}$ gas flow, to suppress oxidation and creating an isothermal contact between the sample and planchet. The temperature distribution inside the sample is assumed to be homogeneous. All TLDs were subjected to the homogeneity test with the method as described by Alawiah et al. (2015).

Samples were placed at a distance of $100 \mathrm{~cm}$ from the source, and irradiated in air with a beam width of $60 \mathrm{~cm}$ and the dose ranging from $1 \mathrm{kGy}$ to $1 \mathrm{MGy}$. The irradiation process was carried out at an ambient temperature using accelerating voltage of $2.5 \mathrm{MeV}$ and the beam current of $1.0 \mathrm{~mA}$. Before the irradiation, the beam output was verified according to the dosimetry protocols of TRS 398 (IAEA, 2000). The measurement was carried out using an electrometer (Wellhofer, Scanditronix) with the cavity volume of $0.65 \mathrm{~cm}^{3}$ (FC65-G) Farmer-type ion chamber. During the sample irradiation measurement, the delivered dose was separately measured by an ionization chamber to check the accuracy of the delivered dose.

Ten samples are allocated for one group of dose range and all samples were read for each TL measurement. A standard clean density glass filter was installed in the reader between the sample and photomultiplier tube, to eliminate unwanted infrared light emitted from the heater component. The samples were readout $24 \mathrm{~h}$ post-irradiation to minimize the low temperature peaks contribution in the glow curve. The glow curves were analyzed by a curve fitting computer program that is known as WinGCF software, which then produce the deconvoluted glow peaks for the kinetic parameters evaluation. WinGCF ${ }^{\mathbb{R}}$ is the commercial software for the TL spectra data analysis. The computerized glow curve deconvolution (CGCD) is an established and a powerful tool for analyzing the TL glow curves and WinGCF ${ }^{B}$ is mainly based on the first order kinetics equation (Randall and Wilkins, 1945).

\section{Results and discussion}

The experimental glow curves by WinREMS ${ }^{\mathbb{1}}$ and the deconvoluted glow peaks by WinGCF ${ }^{\mathbb{B}}$ are presented. The uncertainty of TL response has been determined as \pm 1 standard error of the mean and the coefficient variation did not exceed $\pm 5 \%$, as required for radiotherapy clinical applications (ICRU 24, 1976) and the homogeneity of the samples are maintained. The TLDs also show good reproducibility with a standard deviation less than $3.0 \%$.

\subsection{WinREMS glow curve analysis}

As the TLD reader temperature continues to rise, the TL intensity increases until such time as the population of trapped electrons in the metastable state is sufficiently depleted at which point the TL intensity decreases with further increase in temperature. This will produce the characteristic of TL glow curve, for which consisting of the luminescence peaks in a plot of luminescence intensity versus temperature, as was illustrated schematically by WinREMs software.

As seen in Figs. 1 and 2, the experimental glow curve of TLD100 consists of five peaks, whereas, there is only one peak for GFF, which are constructed by WinREMs application originally from the accumulated TL signal by the TLD reader.

The analyzed glow curves by WinREMS revealed that there are some significant changes in the TLD-100 glow-curve shape with increasing dose in the range of $1 \mathrm{kGy}$ to $5 \mathrm{kGy}$. As shown in Fig. 1, there are only 4 glow peaks (glow peaks 5, 6, 7 and 8 ) visible in the overall temperature range of $60-400{ }^{\circ} \mathrm{C}$. Glow peak 4 was not visible within the UHD dose range of $1 \mathrm{kGy}$ to $5 \mathrm{kGy}$. All glow peak height showed high dependency on UHD by a factor of $\sim 2.5$ to 3 . While, the glow curve of GFF remains constant, with one main peak at the temperature range of $250-350{ }^{\circ} \mathrm{C}$, as the dose increases from 1 to $5 \mathrm{kGy}$.

As shown in Fig. 2, the GFF glow curve was found to be constant in shape, within this dose range. The main peak is located within the temperature range of $250-350{ }^{\circ} \mathrm{C}$.

The TLD-100 of glow peak 4 starts to be visible at $10 \mathrm{kGy}$ in the temperature range of $150-250{ }^{\circ} \mathrm{C}$. Further increased of doses above $10 \mathrm{kGy}$, resulted on peak 5 to be diminished at a dose of $40 \mathrm{kGy}$ (see Fig. 2) and clearly observed the appearance of the new high temperature peaks 7 and 8 in the temperature range of 250$400^{\circ} \mathrm{C}$.

Slight reduction in peak height was observed in glow peaks 5 and 6 while glow peaks 7 and 8 showed a significant increase in peak height by a factor of $\sim 2$. Interestingly, as the dose was increased to $40 \mathrm{kGy}$, glow peaks 5 and 6 were diminished while glow peaks 4,7 and 8, remain visible, with a slight increase in their peak height. As shown in Figs. 1 and 2, glow peak 5 appears within the dose range of 1-10 kGy before being diminished with further increase of dose. The peak height of peak 5 was found to increase with increasing dose from $1 \mathrm{kGy}$ to $4 \mathrm{kGy}$ by $40 \%$ and then decrease by $43 \%$ with further increase of the dose up to $10 \mathrm{kGy}$.

This result was found to be in agreement with other research about peak height response with UHD which was done by Montaño-Garcia and Gamboa-deBuen (2006); they have evaluated the response of TLD-100 to high doses of ${ }^{60} \mathrm{Co}$ gamma rays up to 

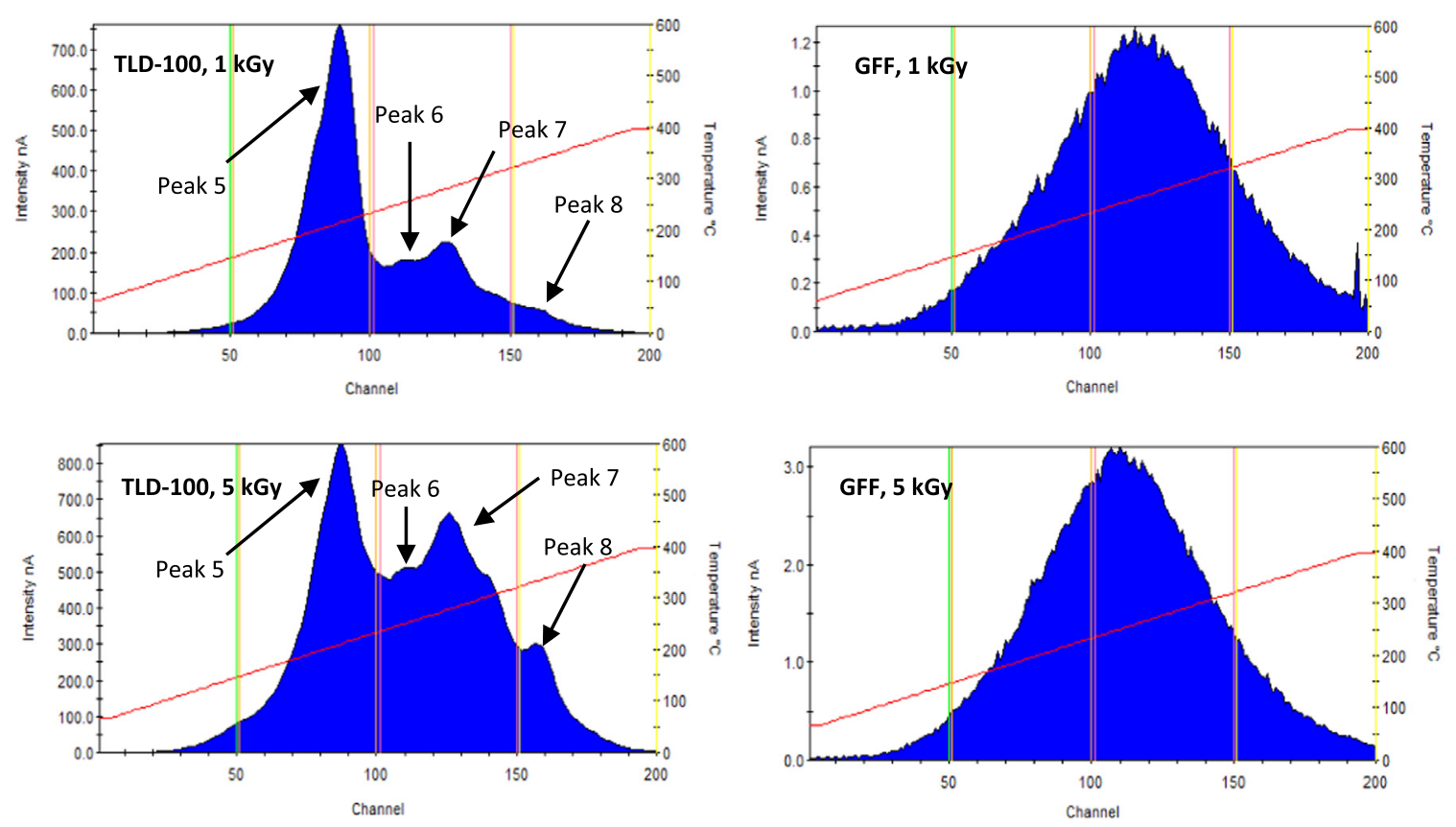

Fig. 1. WinREMS glow curve of TLD-100 and GFF, following $2.5 \mathrm{MeV}$ electron irradiation at doses of $1 \mathrm{kGy}$ and $5 \mathrm{kGy}$.
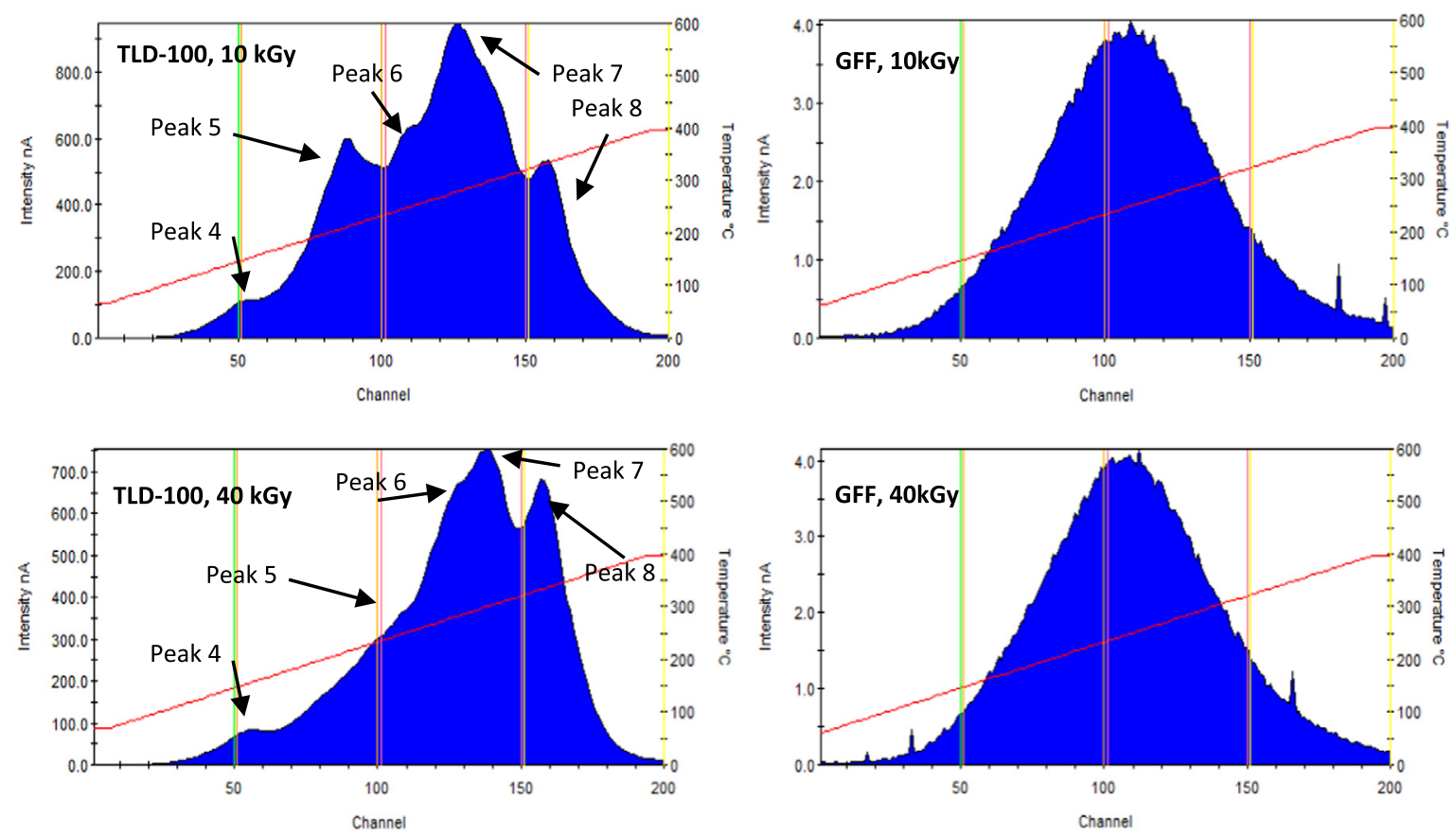

Fig. 2. WinREMS glow curve of TLD-100 and GFF following $2.5 \mathrm{MeV}$ electron irradiation after the doses of $10 \mathrm{kGy}$ and $40 \mathrm{kGy}$.

$10 \mathrm{kGy}$. They observed a significant increase of the peak height of peaks 5 and 7, at the dose of $2.5 \mathrm{kGy}$ and to $7 \mathrm{kGy}$, respectively, and then decrease. In addition, Khoury et al. (2011) found that an increase in dose would cause the TL intensity (peak height) of main dosimetric peak at $218^{\circ} \mathrm{C}$, decreases as the dose increases above $1 \mathrm{kGy}$. Peak 6 was located within the temperature range of $250-350{ }^{\circ} \mathrm{C}$, which is between peaks 5 and 7 in the glow curve structured by WinREMs, as shown in Fig. 1. The appearances of peak 6 can only be visible from the dose range of $1-10 \mathrm{kGy}$ and being diminished following dose $>10 \mathrm{kGy}$.

Glow peak 7 diminished after $100 \mathrm{kGy}$ of UHD whereas glow peaks 4 and 8 remained in the glow curve for doses up to $500 \mathrm{kGy}$, as shown in Fig. 3. As the dose increases, peaks 5 and 6, tend to merge with peaks 7 and 8 (in the temperature range of 250$400{ }^{\circ} \mathrm{C}$ ), which then producing more widely glow curves with lower value of peak height by $20 \%$. The appearance of peaks 7 and 8 is clearly dominant as the dose further increase above $100 \mathrm{kGy}$.

As shown in Fig. 4, the glow curve of GFF remains constant in shape, at $1 \mathrm{MGy}$. The shapes of the glow curves are not significantly changed as a result of increasing dose within the range of UHD. The intensities of all glow curves increase with increasing dose up to $50 \mathrm{kGy}$ and then decreases by $40 \%$ of its original value, with further increasing in dose up to $1 \mathrm{MGy}$. As for TLD-100, peak 4 and peak 8, remain in the glow curve as the dose reached its maximum at $1 \mathrm{MGy}$.

Fig. 5 shows that the normalized TL intensity of TLD-100 increases with increasing dose starts from $1 \mathrm{kGy}$ to $10 \mathrm{kGy}$ and then decreases 

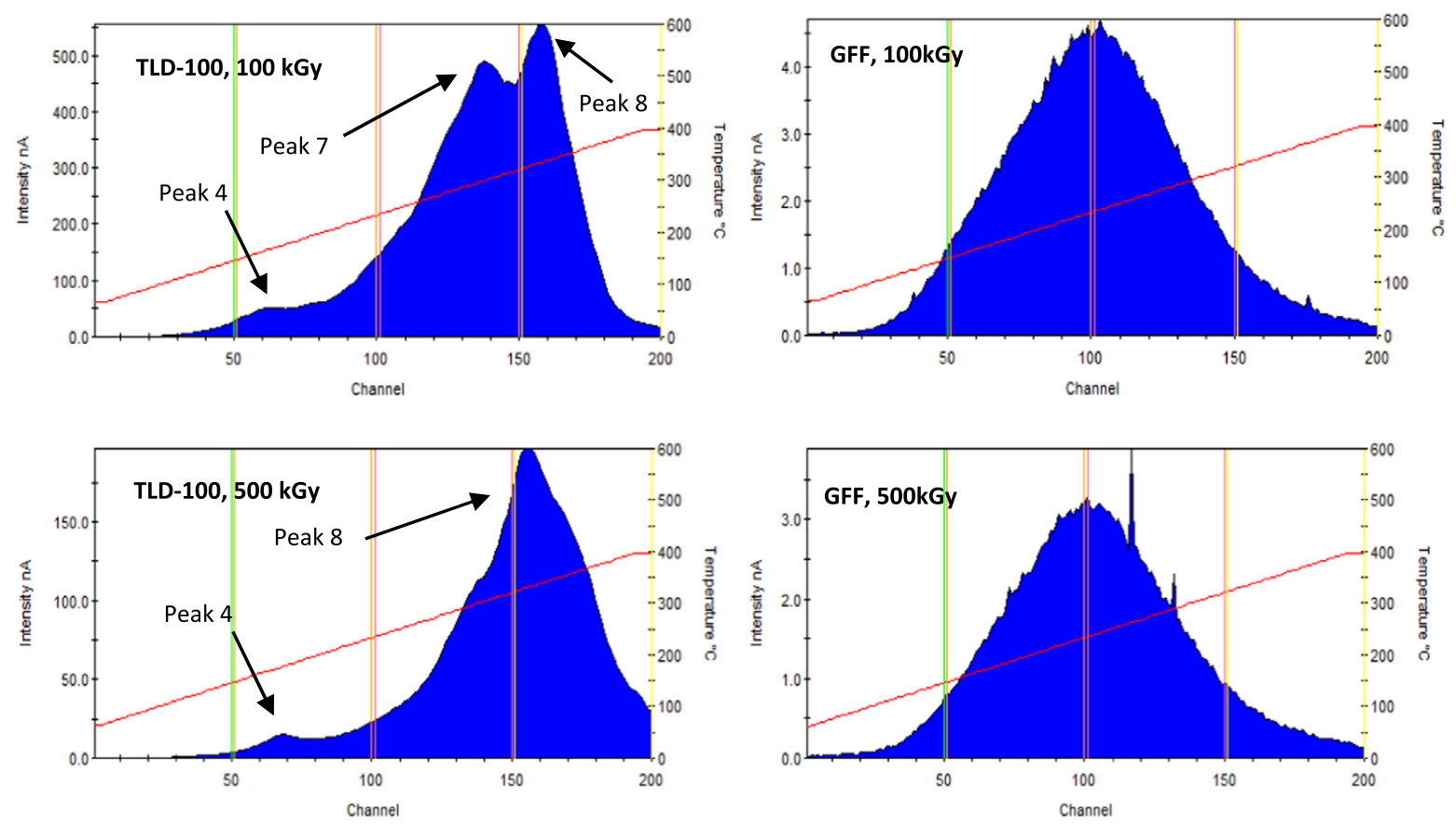

Fig. 3. WinREMS glow curve of TLD-100 and GFF, following $2.5 \mathrm{MeV}$ electron irradiation at doses of $100 \mathrm{kGy}$ and $500 \mathrm{kGy}$.
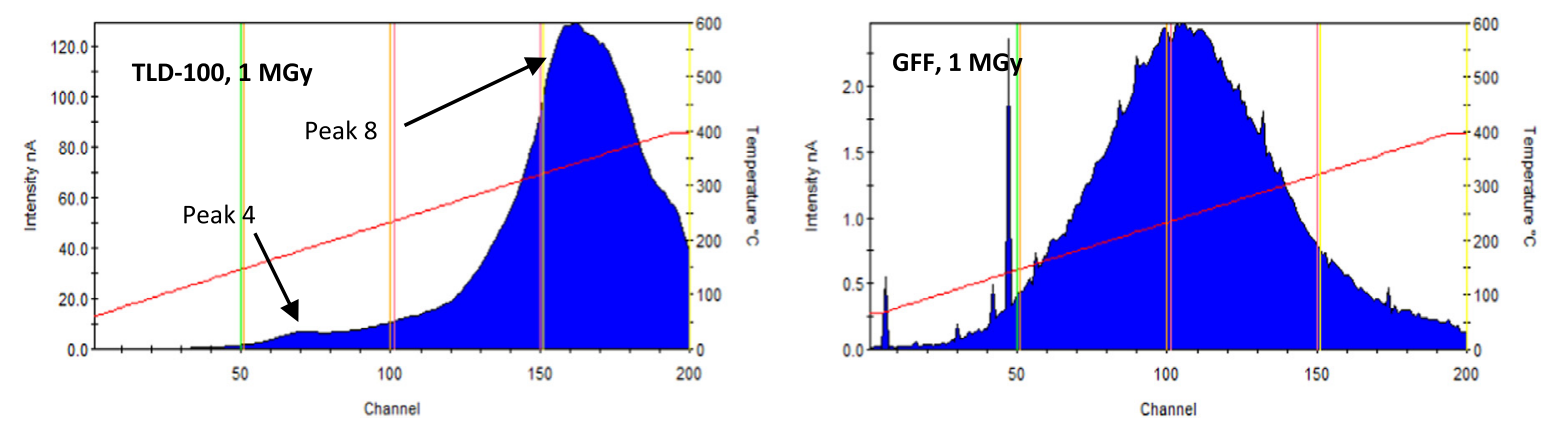

Fig. 4. WinREMS glow curve of TLD-100 and GFF, following $2.5 \mathrm{MeV}$ electron irradiation at doses of $1 \mathrm{MGy}$.

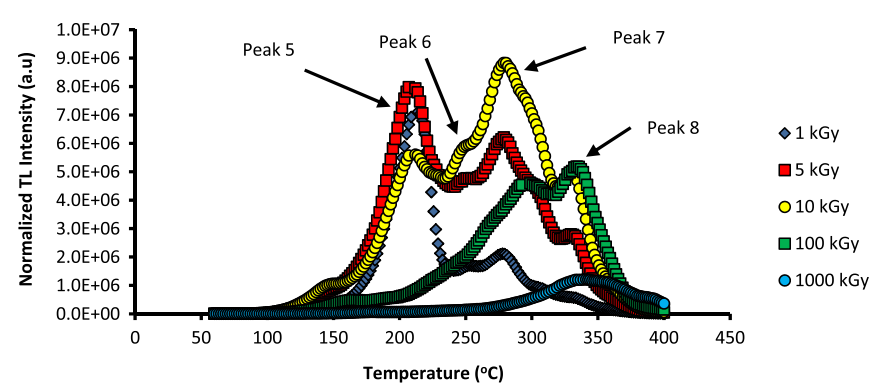

Fig. 5. The variation of TL glow curve of TLD-100 as a function of temperature, following electron irradiation from $1 \mathrm{kGy}$ to $1 \mathrm{MGy}$.

with dose starts from $100 \mathrm{kGy}$ to 1 MGy. Peaks 7 and 8, tend to be shifted to a higher temperature region, within the range of $280^{\circ} \mathrm{C}$ to $305{ }^{\circ} \mathrm{C}$ for peak 7 and $330{ }^{\circ} \mathrm{C}$ to $340{ }^{\circ} \mathrm{C}$ for peak 8 . This result indicates that trapping of electrons at the deep seated traps with higher range of the activation energy of traps. The higher activation energy results in shifting of TL peaks to higher temperatures. These electrons remain trapped until enough thermal energy is available to help them escape and recombine at a luminescent center.

It is also notable, that at lower doses no peak is present in this high temperature range, $270-350{ }^{\circ} \mathrm{C}$. These findings are consistent with the previous results for gamma-ray exposures (Bilski et al., 2008), as well as for protons (Obryk et al., 2010).
Our results were also in agreement with Horowitz et al. (2008), stated that the high temperature peak (HTP) of TLD-100, appears at temperatures above the main dosimetric peak located at $\sim 205^{\circ} \mathrm{C}$ at heating rates of $\sim 1.2 \mathrm{~K} \mathrm{~s}^{-1}$. The maximum intensity of HTP appears at $\sim 270^{\circ} \mathrm{C}$ and is referred as peak 7 (Horowitz et al., 2008).

Horowitz et al. (2008) also found that at a very high dose of gamma/electron irradiation, there is a continuum of TL between peaks 5 and 7 which indicates the presence of at least one additional peak, which is referred to as peak 6. Above peak 7 in temperature, additional peaks appear which have been labeled as peaks 8-10.

It is usually assumed that there is no glow peak beyond $400{ }^{\circ} \mathrm{C}$ since it has also been assumed in the literature that annealing at $400{ }^{\circ} \mathrm{C}$ for $1 \mathrm{~h}$ totally resets the material, emptying all the traps and recombination centers and returns the material to its original/ initial status.

Bilski et al. (2008) found a new peak of temperature exceeds $400{ }^{\circ} \mathrm{C}$ when the TLD $100 \mathrm{H}$ was exposed to the electron irradiation above $50 \mathrm{kGy}$. The glow curve shape was found to be constant at doses ranging from $\mu \mathrm{Gy}$ to a kGy. They also found that the sensitivity loss as the dose increased.

Horowitz et al. (2008) found that at high dose irradiation, they observed the appearance of TL peaks beyond $400{ }^{\circ} \mathrm{C}$. In addition, a small peak was observed near $500{ }^{\circ} \mathrm{C}$ starting at $20 \mathrm{kGy}$. Its 
presence was also reported by Bilski et al. (2010) after irradiation with electrons and by Obryk et al. (2010) after proton irradiation. Khoury et al. (2011) also observed the appearance of a new peak at $420^{\circ} \mathrm{C}$ for the dose range of $700 \mathrm{kGy}$ to $1200 \mathrm{kGy}$ of gamma irradiation.

These findings are found to be contradicted with this study. It is found that, as the dose increases, the high temperature peak (peak 7 and peak 8) appeared and become dominant peaks at the temperature range of $280{ }^{\circ} \mathrm{C}$ to $340^{\circ} \mathrm{C}$ which was not exceeded $400{ }^{\circ} \mathrm{C}$, as shown in Fig. 7. The peak height of peaks 7 and 8 show a significant decrease with increasing dose. The peak 4 of TLD-100 starts to be noticeable at $10 \mathrm{kGy}$ and TL signal tends to decrease with dose up to $1 \mathrm{MGy}$.

In addition, these results are to have good agreement with Khoury et al. (2011) findings on high temperature peak. Khoury et al. (2011) stated that the peaks located at higher temperatures of $317^{\circ} \mathrm{C}$ and $350{ }^{\circ} \mathrm{C}$ of peaks 8 and 9 respectively, which become dominant peaks of the glow curve as the dose increasing. Using gamma irradiation of high dose on TLD-100, Khoury et al. (2011) found that peak height near $315^{\circ} \mathrm{C}$ decreases as the dose increases, and the peak at $350{ }^{\circ} \mathrm{C}$ is dominant up to $300 \mathrm{kGy}$ (Khoury et al., 2011).

It is apparent from this study that increasing the dose results in the growth of the high temperature peaks (HTP). The HTP were peaks 6,7 and 8 with the temperature region at $250{ }^{\circ} \mathrm{C}, 280{ }^{\circ} \mathrm{C}$ and $330^{\circ} \mathrm{C}$, respectively. As the dose increases up to $20 \mathrm{kGy}$, peak 6 merged with peak 7 and peak 8 , which then producing the maximum TL intensity of peaks 7 and 8 at that dose region. Further increase of dose up to $1 \mathrm{MGy}$ caused a significant decrease in TL intensity of 5 times.

Bilski et al. (2010) observed a significant change in the color of the TLDs which at the dose of $46 \mathrm{kGy}$, the TLDs became brownish while at $1 \mathrm{MGy}$ the color changed to dark brown. After readouts, the TLDs returned to their original initial colors. In this research, we also observed a significant color changed from opaque white to light yellow, as the dose increases from $1 \mathrm{kGy}$ to $10 \mathrm{kGy}$, and then the color changed to darker yellow as the dose increases from $10 \mathrm{kGy}$ to $100 \mathrm{kGy}$. Further increases in dose up to $1 \mathrm{MGy}$ resulted in brown color TLDs. We also found that our TLDs showed permanent changes in its color when the dose of irradiation exceeded $10 \mathrm{kGy}$. For that reason, within this work all TLDs were used only once.

It is also found that these results are consistent with Bilski et al. (2010) who stated that the position of the high temperature peak shifts with increasing dose towards higher temperatures, which is about $50{ }^{\circ} \mathrm{C}$ from $75 \mathrm{kGy}$ to $1 \mathrm{MGy}$ (Bilski et al., 2010). The shape of the peak was very well fitted with a first order kinetics function, with the activation energy, $\mathrm{E} \sim 4 \mathrm{eV}$. These results, which were found consistently in all the studied batches, are in a good agreement with those described and discussed in the previous report (Bilski et al., 2008).

The finding seems to be contradicted with Bilski et al. (2010) who used $10 \mathrm{MeV}$ electron exposures and found that TLD-100 exhibited a visible peak at $450{ }^{\circ} \mathrm{C}$ and the shape of glow curves is very similar in all cases. Since, the maximum temperature for peak 8 was found around the temperature range of $330^{\circ} \mathrm{C}$ to $340{ }^{\circ} \mathrm{C}$, which is far from their findings at $450{ }^{\circ} \mathrm{C}$ of the high temperature peak. Another remarkable finding from this research is that the shape of the glow curve showed significant changes with increasing dose, which again contradict with Bilski et al. (2010) who said about similar glow curve shape in all cases.

In case of TLD-100 the glow-curve after dose of $1 \mathrm{MGy}$ is different since it is dominated by two peaks located at about $340{ }^{\circ} \mathrm{C}$ and $370{ }^{\circ} \mathrm{C}$. There is also visible a small peak located at $480{ }^{\circ} \mathrm{C}$ (Bilski et al., 2010). These previous findings are not consistent with the observation on the glow curve of dose $1 \mathrm{MGy}$, showed in this study as one single dominant peak at $340{ }^{\circ} \mathrm{C}$ and no other peak visible after that temperature.

A much smaller shift between 15 and $20^{\circ} \mathrm{C}$ also noticed for the TLD-100 ultra-high temperature peak for doses above $200 \mathrm{kGy}$ (Bilski et al., 2010). This result was consistent with our findings; peak 8 was shifted to smaller temperature difference of $8{ }^{\circ} \mathrm{C}$ for the doses above $250 \mathrm{kGy}$. This is due to the effect of thermally disconnected traps at the dose higher than $200 \mathrm{kGy}$.

For doses lower than $10 \mathrm{kGy}$, almost the whole glow curve appears below $250{ }^{\circ} \mathrm{C}$. While above $10 \mathrm{kGy}$, the peak temperature of a region between 270 and $350{ }^{\circ} \mathrm{C}$ dominates. It is found that peak $7\left(280^{\circ} \mathrm{C}\right)$ can be used for dosimetry starting from $1 \mathrm{kGy}$ and before it diminished above $250 \mathrm{kGy}$. Peak $8\left(330^{\circ} \mathrm{C}\right)$ starts to be useful at about $2 \mathrm{kGy}$ and it will not be saturated for the dose up to $1 \mathrm{MGy}$. We also observed a strange behavior of peak $4\left(150^{\circ} \mathrm{C}\right)$ which starts to be visible at about $10 \mathrm{kGy}$ and will remain visible, of the dose up to $1 \mathrm{MGy}$. In this way the whole range from $1 \mathrm{kGy}$ to $1 \mathrm{MGy}$ is covered.

\subsection{WinGCF deconvoluted peak analysis}

As seen in Fig. 6, there are 5 deconvoluted peaks, which denoted as peaks 4, 5, 6, 7 and 8 . It is observed, as the dose increases from $1 \mathrm{kGy}$ to $10 \mathrm{kGy}, E_{a}$ decreases within $15-48 \%$ (except for peaks 6 and 8 ). All peaks were shifted to the lower temperature region by $1.4-12 \%$ and the peak integral of all peaks increased up to 10 times of its initial value. As the dose was further increased from $100 \mathrm{kGy}$ to $1 \mathrm{MGy}, E_{a}$ is observed to increase by $\sim 70 \%$ with dose (except for peaks 6 and 8), $T_{\max }$ is increased by $\sim 2.9-4.4 \%$ (except for peak 5) and peak integral shows a significant decrease by 10 times, as shown in Figs. 7 and 8 .

Considering the simple model with and without the effect of thermally disconnected traps, the discussion is based on TL glow curve shape and behavior of the TLD-100 samples. WinREMS provided the experimental data of glow curve and then extracted and analyzed by WinGCF for determining the kinetic parameters associated with the charge transfer process in the samples. These parameters include the activation energy, $E_{a}$, maximum peak temperature, $T_{\max }$ and peak integral, $P I$.

The two assumptions are normally employed includes; (1) that the free carrier concentration in the conduction band is always very much less than the trapped carrier concentration, and (2) that the rate of change of the free carrier concentration is always very much less than the rate of change of the trapped carrier concentration. According to the criteria of Randall and Wilkins (1945) the TL models yield the first order kinetics Eq. (1) if the probability of retrapping is negligible compared with the probability of recombination.

$$
\begin{aligned}
I(T)= & -\frac{1}{\beta} \frac{\mathrm{d} n}{\mathrm{~d} t}=n_{o} \frac{s}{\beta} \exp \left\{-\frac{E}{k T}\right\} \\
& \times \exp \left\{-\frac{s}{\beta} \int_{T_{o}}^{T} \exp \left\{-\frac{E}{k T^{\prime}}\right\} \mathrm{d} T^{\prime}\right\}
\end{aligned}
$$

Eq. (1) is the Randall and Wilkins first-order kinetic expression of a single glow peak.

Based on this model regarding the variation of $n_{0}$, it can be noted that as the initial concentration, $n_{o}$, increases, the peak height increases but the maximum peak temperature remain constant (Chen and McKeever, 1997). The peak position stays fixed, while the height of peak is directly proportional with $n_{o}$. This is an important characteristic of all first-order TL glow curves. In the application of dosimetry, $n_{o}$ is the parameter that is proportional to the absorbed dose. And the area under the glow peak is equal to $n_{o}$ since $n_{\infty}$ is zero for $t \rightarrow \infty$, see Eq. (2) (Bos et al., 2001). 

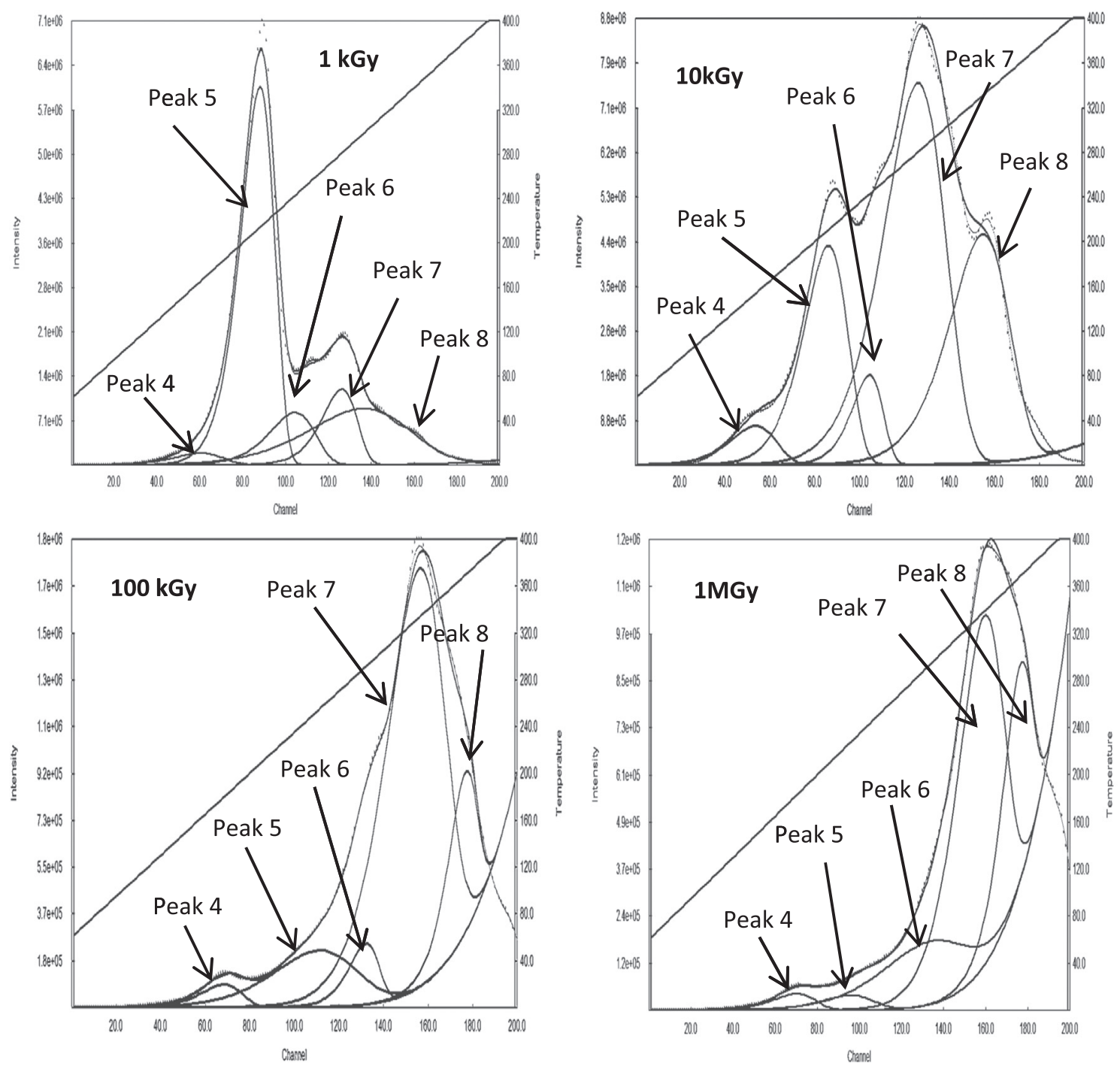

Fig. 6. A WinGCF deconvolved glow peaks of TLD-100 for the ultra-high dose of $1 \mathrm{kGy}, 10 \mathrm{kGy}, 100 \mathrm{kGy}$ and $1 \mathrm{MGy}$, electron radiation $2.5 \mathrm{MeV}$.

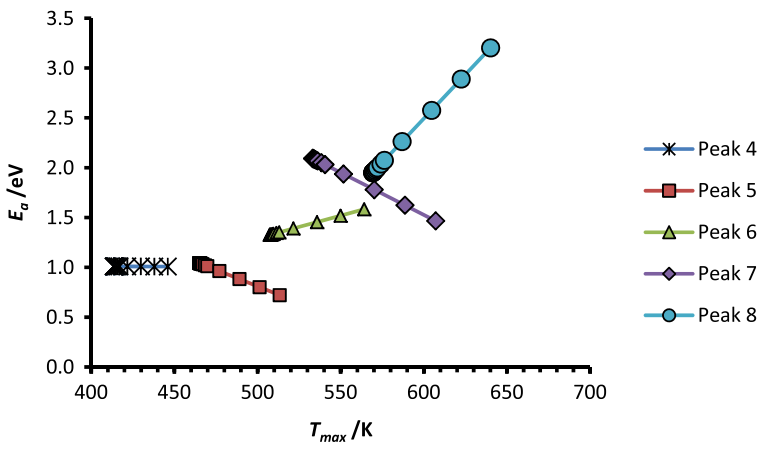

Fig. 7. The kinetic parameter variation of $E_{a}$ on $T_{\max }$ of TLD-100.

$\int_{0}^{\infty} I(t) \mathrm{d} t=-\int_{0}^{\infty} \frac{\mathrm{d} n}{\mathrm{~d} t} \mathrm{~d} t=-\int_{n_{0}}^{n_{\infty}} \mathrm{d} n=n_{0}-n_{\infty}$

Also stated in the first order kinetic, that as the activation energy increases, the peak position shifts to much higher temperature region with decreasing peak height and increase in peak width while keeping the area constant.

On the other hand, Garlick and Gibson (1948) considered the possibility of retrapping, given by Eq. (3).

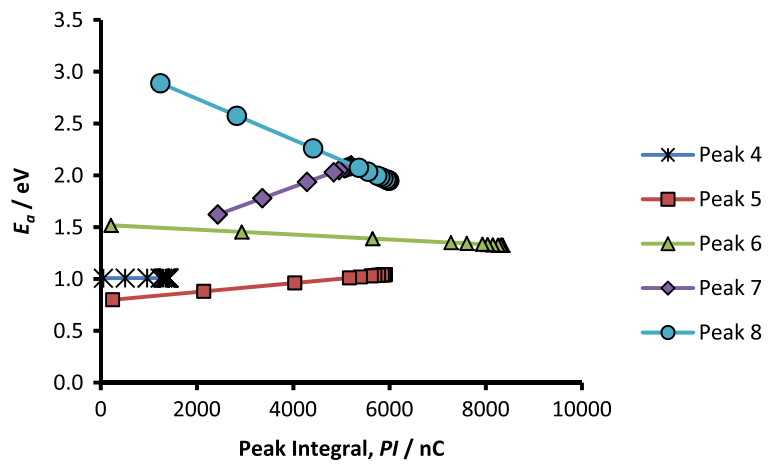

Fig. 8. The kinetic parameter variation of $E_{a}$ on PI of TLD-100.

$I_{T L}=\left(\frac{n_{o}^{2}}{N}\right) \operatorname{sexp}\left\{-\frac{E_{t}}{k T}\right\}\left[1+\left(\frac{n_{o} s}{\beta N}\right) \int_{T o}^{T} \exp \left\{-\frac{E_{t}}{k \theta}\right\} d \theta\right]^{-2}$

Based on second-order kinetic, as the $n_{0}$ increases, the peak height shows a significant increase and peak position shifts to the much lower temperature region, with additional characteristics of wider (slightly broader) and more symmetric peak compared to the first-order peak. This is due to the significant concentrations of 
released electrons are retrapped before recombine, thus giving rise to a delay in the luminescence emission and a spreading out of the emission over a wider temperature range.

It is observed that Peaks 6 and 8 were exhibited the first-order kinetic peak response, as the $E_{a}$ increases with increasing $T_{\max }$, as shown in Fig. 7. In contrast, peaks 5 and peak 7 exhibiting the opposite response of $E_{a}$ with $T_{\max }$. It is also observed not much change of $E_{a}$ for Peak 4 as $T_{\max }$ increasing.

To confirm the first-order peak kinetic behavior, the peak integral of all peaks is compared. Fig. 8 shows the variation in $E_{a}$ with changes in PI. It is observed that Peaks 6 and 8 were exhibited the first-order kinetic peak response, as the $E_{a}$ decreases with increasing $P I$, whereas Peaks 5 and 7 exhibiting the opposite response of $E_{a}$ with PI and thus are not showing the behavior of firstorder kinetic peaks. It is concluded that Peak 6 and 8 are the firstorder kinetic peaks and can be used as the main dosimetric peak at both low and high temperatures. The average $T_{\max }$ of Peak 6 and 8 is $250{ }^{\circ} \mathrm{C}$ and $340{ }^{\circ} \mathrm{C}$, respectively. Thus, Peak 6 is the dominant peak at lower temperature region, while Peak 8 is the dominant peak at higher temperature.

In variation with dose, the observations on WinREMS glow curves (LTP) are best described by the second-order kinetic Garlick and Gibson TL model. It is noted earlier that $n_{o}$ is proportional to the absorbed dose. As the dose increases from $1 \mathrm{kGy}$ to $10 \mathrm{kGy}$, Peak 6 position shifts to much lower temperature region from 254 to $250^{\circ} \mathrm{C}$ with increasing peak height, exactly as predicted by second-order kinetic model. Peak 5 also exhibits the same behavior, as the glow peak shifts from 214 to $210^{\circ} \mathrm{C}$ as the dose increases from $1 \mathrm{kGy}$ to $5 \mathrm{kGy}$.

In contrast, for the HTP behavior in response to the dose variation, are successfully explained by first-order kinetic Randall and Wilkins TL model. As stated earlier, it is classified that the following peak $7\left(280^{\circ} \mathrm{C}\right)$ and $8\left(330^{\circ} \mathrm{C}\right)$ as HTP according to its temperature. As the dose increases from $1 \mathrm{kGy}$ to $10 \mathrm{kGy}$, the positions of peaks are constant and the peak height shows a significant increase with dose. This finding is as expected in firstorder kinetic model.

This combination of order of kinetic which occurred in the same glow curve, where Peaks 5 and 6 are exhibited the secondorder behavior while Peaks 7 and 8 are more prone to the firstorder kinetics, with the LTP shifts to the lower temperature region and drags parts of the glow curve and then producing wider and broader glow curve, as the dose increases from $1 \mathrm{kGy}$ to $10 \mathrm{kGy}$.

Mostly all peaks showed the maximum TL intensity at the dose of $10 \mathrm{kGy}$ and further increased in dose after that point, exhibited a significant decreased in TL intensity. It is called the critical dose limit of this TL material. Since Peaks 5 and 6 were diminished after $10 \mathrm{kGy}$ (refer to the TL glow curve illustrated in blue), so the discussion on higher dose region that is mostly greater than the critical dose limit ( $>10 \mathrm{kGy}$ ) will be based on Peaks 4, 7 and 8 . It is noticed that peak 4 starts to be visible after the dose of $10 \mathrm{kGy}$.

As the dose increases from $10 \mathrm{kGy}$ to $1000 \mathrm{kGy}$, Peak 8 position shifts to a much higher temperature region within the range of $330-340{ }^{\circ} \mathrm{C}$ and peak height decreasing with dose by $80 \%$. It is observed the same behavior in Peak 7 and Peak 4. It is found that none of kinetics model can explain this interesting behavior at extremely high doses especially after the critical dose limit of $10 \mathrm{kGy}$. It is also noticed the strange behavior of Peak 4, which tends to be invisible at the lower dose $(<10 \mathrm{kGy})$ and starts to be appeared at the critical dose limit of $10 \mathrm{kGy}$.

\subsection{Supralinearity}

The property of supralinearity is related to the application of TL in dosimetry and is presented quantitatively by the supralinearity index, $f(D)$. Supralinearity index, $f(D)$, is given by Eq. (4), where $D$

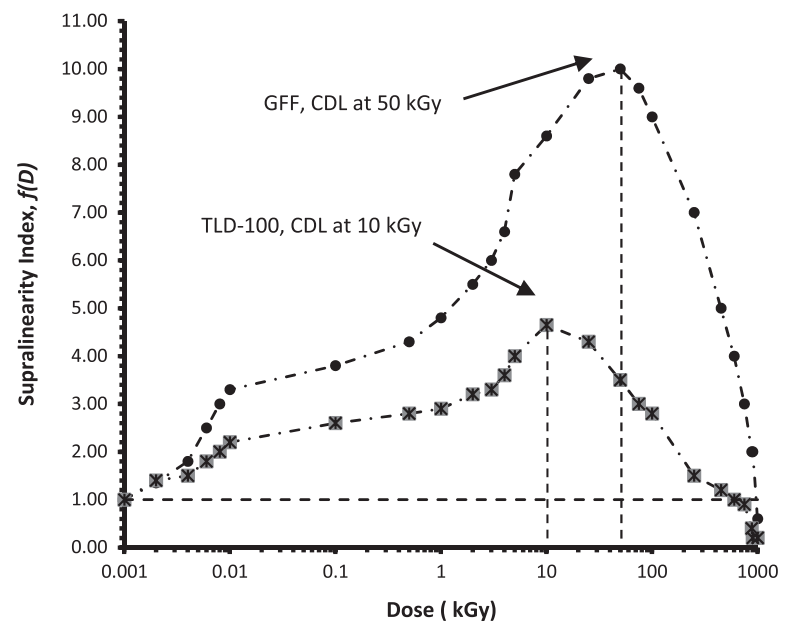

Fig. 9. The supralinearity index as a function of ultra-high dose of TLD-100 and GFF, following $2.5 \mathrm{MeV}$ electron for doses up $1 \mathrm{MGy}$.

is the actual dose, $D_{o}$ is the calibration dose level and $I$ is the intensity of TL signal. Generally, the supralinear dose response is a characteristic of TLD-100, over 1 Gy of dose.

$f(D)=\left[\frac{I(D)}{D}\right] /\left[\frac{I\left(D_{o}\right)}{D_{o}}\right]$

Supralinearity is one of the nonlinear dose dependence effects, which grows to much higher values at a certain dose range, before reducing to low values when saturation effects become dominant (Chen and Hag-Yahya, 1996). Many models explaining the nonlinear effects with different perspective, such as; (1) that related to excitation stage, or (2) that related to heating phase and (3) types of radiation (UV, gamma rays, $\mathrm{x}$-rays, $\alpha$ particle, $\beta$ particle, electron and many more) (Chen and McKeever, 1997). The competing trap model by Kristianpoller et al. (1974), stated that the supralinear effect is mainly due to the competition during excitation and heating, which created the quadratic total dose dependence. The supralinear response was found to be proportional to the concentration of charge carrier in both traps and luminescence centers in the presence of a strong competitor. Instead, Banerjee (2001) suggested that supralinearity is dependent on the recombination cross-section, the thermal velocity of the carriers and the concentration of the recombination centers. The Unified Interaction Model (UNIM) by Horowitz (2001), explained that gamma-ray induced supralinearity at high doses arises from the decreasing efficiency of the competitive non-radiative processes relative to the luminescence recombination process.

It is clearly visible in Fig. 9, that the linearity index, $f(D)>1$, which indicates that the TLD-100 and GFF exhibit the supralinearity response over the wide range of doses, up to $1 \mathrm{MGy}$. The supralinearity index $f(D)$ of TLD-100, increases by a factor of 3 as the dose increases from $1 \mathrm{kGy}$ to $10 \mathrm{kGy}$. It is found that the supralinearity index reached its maximum at $10 \mathrm{kGy}$. In this study, this point is denoted as the Critical Dose Limit (CDL) of the dosimeter. Further increases in dose after the CDL of TLD-100, resulted in a significant decrease of $f(D)$ by a factor of 9 within the dose range of $10 \mathrm{kGy}-1 \mathrm{MGy}$. It is also found that when the dose increases over the CDL, the peak height of TLD-100 decreases by a factor of 4 , and the whole glow curve was slightly shifted to the higher temperature region by $10^{\circ} \mathrm{C}$. The glow curve was also observed to be increased in width.

On the other hand, the supralinearity index of GFF increases rapidly, as the dose increases from $1 \mathrm{kGy}$ to $50 \mathrm{kGy}$. The CDL of 


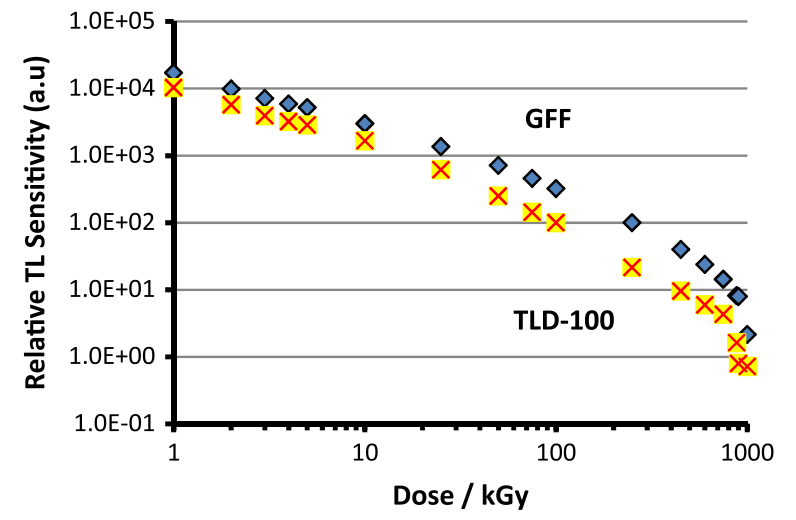

Fig. 10. Relative TL sensitivity as a function of ultra-high dose of TLD-100 and GFF following $2.5 \mathrm{MeV}$ electron irradiation.

GFF, occurs at the dose of $50 \mathrm{kGy}$. After the CDL is achieved, the width of the glow curve increases, the peak height decreases by $40 \%$ and the whole glow curve is slightly shifted to the lower temperature region by $4 \%$.

In this research, it was observed that no saturation effects for the TLD-100 and GFF samples within the studied dose range. This finding is contradicted to Chen and Hag-Yahya (1996), who stated that the saturation effects become dominant at much higher values at a certain dose range. It is also found that, further increase in dose, after the CDL point, causes a significant decrease in the supralinearity index, $f(D)$ of the TL material. However, Horowitz (2001), found that the decrease in TL after it reached the maximum value, was attributed to the saturation or damage effects. We also found that annealing the TLD-100 and GFF with temperature more than $400{ }^{\circ} \mathrm{C}$ is required to reset it back to its original condition, following radiation doses up to $1 \mathrm{MGy}$.

\subsection{TL Sensitivity}

The TL sensitivity (amount of TL signal per unit of absorbed dose) depends on several experimental and material variables. These variables include the batch of material, the annealing procedure, the heating rate, the glow curve region of integration, and the spectral response of the photomultiplier tube used in the TLD reader. It is customary to use TLD-100 as the standard reference by its relative sensitivity (Moscovitch and Horowitz, 2007).

The relative sensitivity of the FF samples is presented here in Fig. 10. The GFF shows a good sensitivity at ultra-high dose of electron irradiation.

Fig. 10 shows the dose dependency of TL sensitivity in GFF studied with TLD-100 as the reference material. It is observed a significant decrease in TL sensitivity as the dose increases within the range of $1 \mathrm{~Gy}$ to $1 \mathrm{MGy}$, for all samples. The observation was in agreement with the TL studies using ${ }^{60} \mathrm{Co}$ gamma ray irradiation at $0.1 \mathrm{MGy}$ that were performed by Bilski et al. (2008), who found sensitivity loss as the dose increased. In this study, it is also found that the G FF showed a substantially greater TL sensitivity than that of TLD-100 by 4.8 times. The decrease in sensitivity is related to the effects of the deep traps (McKeever et al., 1997). In this study, we propose the loss in sensitivity at UHD might be contributed with the loss of electron energy when interacting with the inner shell atomic electron, which has a stronger nuclear force compared with the outer shell electrons.

\section{Conclusion}

UHD radiation allowed us to determine the maximum limit of radiation of each dosimeter. The TL model is valid to explain the changes in TL kinetic parameters of TLD-100 at UHD. The TL response at UHD revealed the abnormal behavior of peak 4 of TLD100 , and might be an important clue to understand the behavior of TLD-100 at extremely high dose range. The supralinearity response at UHD showed the limitations of the TL kinetic models when dealing with the behavior of kinetic parameters of the studied glow peaks. One notable finding which showed that the TL kinetic model can be used and valid to explain the behavior of glow peak before the CDL is achieved, whereas none of the TL models can explain the strange changes in TL glow peak at the dose more than $10 \mathrm{kGy}$ up to $1 \mathrm{MGy}$.

\section{Acknowledgments}

This work was supported by University of Malaya (UM)-Ministry of Higher Education Malaysia (MOHE) High Impact Research (HIR) Grant H-21001-00-F000033, UM-MOHE HIR Fiber Pulling Grant A000007-50001 and MMU-MOHE FRGS Research Grant EP20120521004. We are indebted to the Alurtron, Nuclear Malaysia Agency, Malaysia and the technical staff who were actively involved during the irradiation task, which includes En. Muhamad Zahidee b. Taat, En. Shari b. Jahar, En. Abdul Basit b. Shafiei and En. Azmi for the technical set-up of an electron beam accelerator. The authors would like to acknowledge En. Mohd Azizi b. Mohd Jali for the technical support on the use of the TLD reader and other related equipment in Nuclear Malaysia Agency, Malaysia.

\section{References}

Alawiah, A., Bauk, S., Abdul-Rashid, H.A., Gieszczyk, W., Hashim, S., Mahdiraji, G.A., Tamchek, N., Bradley, D.A., 2015. Potential application of pure silica optical flat fibers for radiation therapy dosimetry. Radiat. Phys. Chem. 106, 73-76.

Banerjee, D., 2001. Supralinearity and sensitivity changes in optically stimulated luminescence of annealed quartz. Radiat. Meas. 33, 47-57.

Bilski, P., Obryk, B., Stuglik, Z., 2010. Behaviour of LiF: Mg,Cu,P and LiF: Mg,Ti thermoluminescent detectors for electron doses up to 1 MGy. Radiat. Meas. 45 576-578.

Bilski, P., Obryk, B., Olko, P., Mandowska, E., Mandowski, A., Kim, J.L., 2008. Characteristics of LiF: Mg,Cu,P thermoluminescence at ultra-high dose range. Radiat. Meas. 43, 315-318.

Bos, A.J.J., 2001. High sensitivity thermoluminescence dosimetry. Nucl. Instrum. Methods B 184, 3-28.

Chen, R., McKeever, S.W.S., 1997. Theory of Thermoluminescence and Related Phenomena. World Scientific, London.

Chen, R., Hag-Yahya, A., 1996. Interpretation of very high activation energies and frequency factors in TL as being due to competition between centres. Radiat. Prot. Dosim. 65 (1-4), 17-20.

Garlick, G.F.J., Gibson, A.F., 1948. The electrons trap mechanism of luminescence in sulphide and silicate phosphors. Proc. Phys. Soc. 60, 574-590.

Horowitz, Y.S., Horowitz, A., Oster, L., Marino, S., Datz, H., Margaliot, M., 2008. Investigation of the ionisation density dependence of the glow curve characteristics of LIF: MG, TI (TLD-100). Radiat. Prot. Dosim. 131 (4), 406-413.

Horowitz, Y.S., 2001. Theory of thermoluminescence gamma dose response: the unified interaction model. Nucl. Instrum. Methods Phys. Res. Sect. B 184, 68-84.

IAEA, 2000. Absorbed Dose Determination in External Beam Radiotherapy: An International Code of Practice for Dosimetry Based on Standards of Absorbed Dose to Water. Technical Report Series, vol. 398. Vienna-Austria.

ICRU report No. 24., 1976. Determination of Absorbed Dose in a Patient Irradiated by Beams of X or Gamma Rays in Radiotherapy Procedures. International Commission on Radiation Units and Measurements (ICRU), Washington, D.C.

Khoury, H.J., Obryk, B., Barros, V.S., Guzzo, P.L., Ferreira, C.G., Bilski, P., Olko, P., 2011 Response of TL lithium fluoride detectors (MTS) to high gamma radiation doses. Radiat. Meas. 46, 1778-1881.

Kristianpoller, N., Chen, R., Israeli, M., 1974. Dose dependence of thermoluminescence peaks. J. Phys. D: Appl. Phys. 7, 1063-1072. 
McKeever, S.W.S., Agersnap Larsen, N., Bùtter-Jensen, L., Mejdahl, V., 1997. OSL sensitivity changes during single aliquot procedures: computer simulations. Radiat. Meas. 27, 75-82.

Montaño-Garcia, C., Gamboa-deBuen, I., 2006. Measurements of the optical density and thermoluminescent response of LiF: Mg,Ti exposed to high doses of ${ }^{60} \mathrm{Co}$ gamma rays. Radiat. Prot. Dosim. 119 (1-4), 230-232.

Moscovitch, M., Horowitz, Y.S., 2007. Thermoluminescence materials for medical applications: LiF: Mg,Ti and LiF: Mg, Cu, P. Radiat. Meas. 41, S71-S77.
Obryk, B., Bilski, P., Glaser, M., Fuerstner, M., Budzanowski, M., Olko, P., Pajor, A., 2010. The response of TL lithium fluoride detectors to $24 \mathrm{GeV} / \mathrm{c}$ protons for doses ranging up to 1 MGy. Radiat. Meas. 45, 643-645.

Puchalska, M., Bilski, P., 2006. GlowFit: a new tool for thermoluminescence glowcurve deconvolution. Radiat. Meas. 41, 659-664.

Randall, J.T., Wilkins, M.H.F., 1945. Phosphorescence and electron traps. I. The study of trap distributions. Proc. R. Soc. Sci. Lond. A 184, 366-389. 